\title{
Hopeless to hopeful: Management of an endo-perio lesion with an interdisciplinary approach
}

Pramod VT1 ${ }^{1}$ Shobhaprakash², Sadiya $\mathrm{S}^{3}$

Senior Lecturer ${ }^{1}$, Professor \& Head ${ }^{2}$, Department of Periodontics, College of Dental Sciences, Davangere

Private practicioner ${ }^{3}$, The Dentist clinic, Mangalore.

\begin{abstract}
:
Endodontic-periodontal lesions pose challenge to the clinician as far as diagnosis and prognosis of the involved teeth are concerned. The pathways for the spread of bacteria between pulpal and periodontal tissues are controversial. Treatment and prognosis of endodontic-periodontal diseases vary and depend on the cause and the correct diagnosis of specific condition .This case report describes a successful treatment of a 44 year old male patient who reported with a chief compliant of pain in the right upper and lower tooth back region of the jaw since 20 days. Clinical examination revealed deep pockets and furcation involvement between maxillary right first and second molars. Radiographic examination showed bone loss and furcation involvement. Non-vital root resection with maxillary first molar was planned. Prior to root resection, root canal treatment was performed and then rehabilitated with full metal crown.
\end{abstract}

Keywords: Endodontic-periodontal lesions, furcation involvement, root resection,

\section{Introduction}

The relationship between periodontal and pulpal disease was first described by Simring and Goldberg in $1964 .^{1}$ Since then the term endo-perio lesion has been used to describe lesions due to inflammatory products found in varying degrees in both the periodontium and the pulpal tissues. Endodontic-Periodontic lesionmay be defined as a periodontally involved tooth with pulp necrosis and infection where the necrosis may be partial , involving all pulpal tissues extending from the pulpal chamber to the foramen. Recently the term Pulpodontic - periodontic syndrome has been used in relation with endoperio lesions ${ }^{2}$. This syndrome involves inflammation or degeneration of the pulp with a periodontal pocket adjacent to the same tooth. which can be initiated by either pulpal or periodontal disease and may manifest pulpal or periodontal symptoms., ${ }^{2,3}$

Classification of endodontic-periodontal lesions ${ }^{3,4}$ : Simon, Glick and Frank ${ }^{3}$ (1972) separated the lesions of both periodontal and pulpal tissues into the following groups :

1. Primary endodontic lesions

2. Primary periodontal lesions.

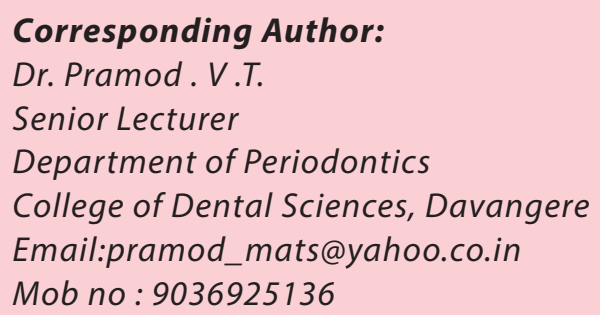

3. Primary periodontal lesions with secondary endodontic involvement

4. Primary endodontic lesions with secondary periodontal involvement

5. True combined lesions

Diagram no: 1

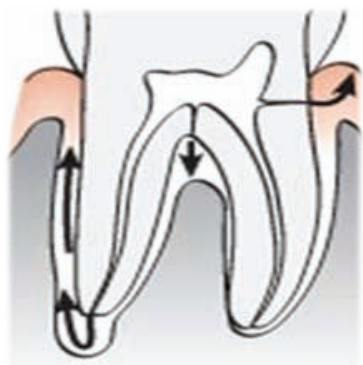

Originally an endodontic problem, with fistulisation from the apex \& along the root to the gingiva.
Diagram no: 2

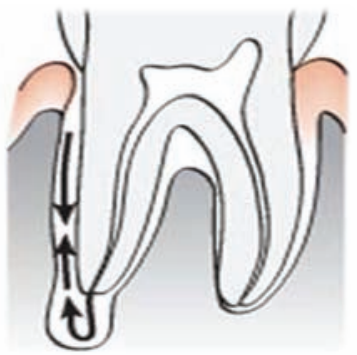

Long-standing periapical lesion draining through the periodontal ligament can become secondarily complicated,leading to retrograde periodontitis.

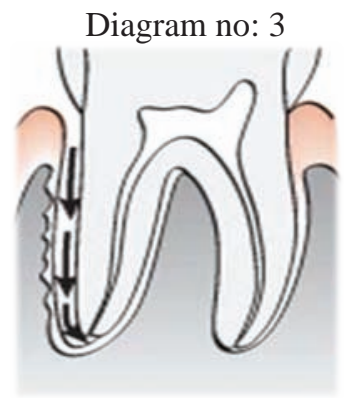

Periodontal pocket can deepen to the apex \& secondarily involve the pulp. 
Diagram no: 4

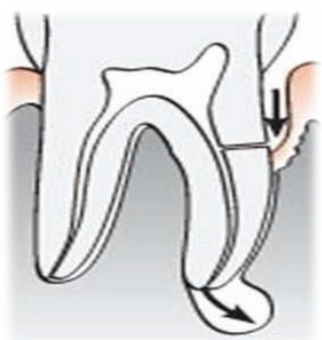

Periodontal pocket can infect the pulp through lateral canal, which in turn can result in a periapical lesion.

Etiopathogenesis of spread of infection between pulpal and periodontal tissues²:

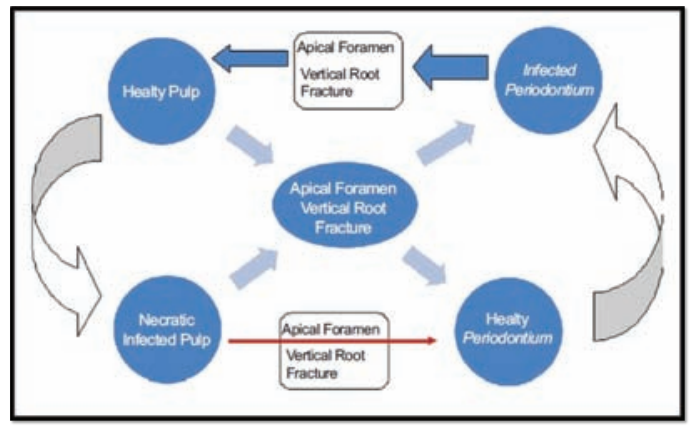

Diagram no: 6

\section{Characteristic features of endo-perio} lesions $^{6}$ :

\begin{tabular}{|c|c|c|c|c|c|}
\hline Lesion & Pain & Swelling & $\begin{array}{c}\text { Periodontal } \\
\text { pocketing }\end{array}$ & Radiograhic features & Vitality \\
\hline $\begin{array}{c}\text { Primary } \\
\text { endodontic }\end{array}$ & $\begin{array}{c}\text { Moderate to } \\
\text { severe }\end{array}$ & Possible & $\begin{array}{c}\text { None unless } \\
\text { sinus tract }\end{array}$ & $\begin{array}{c}\text { Possible periapical } \\
\text { radiolucency }\end{array}$ & Non-vital \\
\hline $\begin{array}{c}\text { Primary } \\
\text { endodontic } \\
\text { secondary } \\
\text { periodontic }\end{array}$ & $\begin{array}{c}\text { Moderate to } \\
\text { severe }\end{array}$ & Likely & $\begin{array}{c}\text { Evident or } \\
\text { sinus tract }\end{array}$ & $\begin{array}{c}\text { Radiolucency from } \\
\text { apex to } \\
\text { sulcus,decreasedcrestal } \\
\text { bone height }\end{array}$ & Non-vital \\
\hline $\begin{array}{c}\text { Primary } \\
\text { periodontic }\end{array}$ & $\begin{array}{c}\text { None to } \\
\text { moderate }\end{array}$ & Possible & Moderate & $\begin{array}{c}\text { Decreased crestal } \\
\text { height }\end{array}$ & Vital \\
\hline $\begin{array}{c}\text { Primary } \\
\text { periodontic } \\
\text { secondary } \\
\text { endodontic }\end{array}$ & $\begin{array}{c}\text { None unless } \\
\text { acute endo }\end{array}$ & Possible & Severe & $\begin{array}{c}\text { Bone loss approaching } \\
\text { apex }\end{array}$ & Vital \\
\hline $\begin{array}{c}\text { Combined } \\
\text { pulpal- } \\
\text { periodontal }\end{array}$ & $\begin{array}{c}\text { Moderate to } \\
\text { severe }\end{array}$ & Likely & $\begin{array}{c}\text { Severe,connects } \\
\text { with periapex }\end{array}$ & $\begin{array}{c}\text { Bone loss extending to } \\
\text { apex }\end{array}$ & Non-vital \\
\hline
\end{tabular}

\section{Case Report}

A 44 year old systemically healthy male patient who reported to our out patient department with a chief compliant of pain in the right upper and lower tooth back region of the jaw since 20 days. He had history of pain which was gradual in onset, dull aching type and intermittent in nature which aggravated on mastication and relieved on rest. Patient had undergone extraction in lower tooth back region 3 years back for decay in a private dental clinic On thorough intra oral examination, 16 and 17 presented with grade I mobility. Periodontal probing revealed isolated $8 \mathrm{~mm}$ pocket in distobuccal region of 16. Probing under local anesthesia with Naber's probe revealed a definitive horizontal and vertical component of bone loss.Glickman's grade II furcation involvement with 17 and grade III furcation involvement with 16 were seen. Supra eruption was seen with 17, width of attached gingival was inadequate in relation to 16,17 region (Fig 1). On intra oral periapical radiographic examination furcation involvement in relation to 16,17 and extensive periradicular bone loss irt distobuccal root of 16 was seen (Fig 2). Based on clinical and radiographic findings prognosis in relation to 16,17 was considered as fair. Electric pulp testing was done to check for tooth vitality, which confirmed that the tooth was nonvital. Based on the above findings 16 was diagnosed with endo-perio lesion.The present endo-perio lesion with respect to 16 can be classified under primary periodontic and secondary endodontic lesion.

Patient was scheduled for initial non surgical periodontal therapy and intentional endodontic treatment. Non surgical therapy outcomes showed significant improvements in bleeding on probing, probing pocket depth and clinical appearance of gingiva. Root canal treatment procedure in relation to 16 was performed (Fig-3) patient was recalled after 2 weeks for re-evaluation. Later patient was scheduled for surgical phase of periodontal therapy after necessary blood investigations. Kirkland flap technique was employed to reflect mucoperiosteal flap (Fig-4) and thorough debridement of furcation area was done.Surgical therapy included open flap debridement and root resection of distobuccal root of 16 with platelet rich fibrin and bone graft placement. Initially full thickness muco periosteal flap was raised on the buccal side, and then the distobucal root of 16 was cut with a no. 2 carbide bur till the bifurcation was reached (Fig-5). Once the separation was complete the distobuccal root was removed by delivering it buccally. The furcation area was trimmed (Fig-6) to ensure that no residual debris was present that could cause further periodontal irritation. Platelet rich fibrin membrane (PRF) was prepared with required quantity of blood drawn in $10 \mathrm{ml}$ test tubes without an anticoagulant and centrifuged immediately using a tabletop centrifuge for 12 minutes at 2,700 rpm10. 
Fig -1

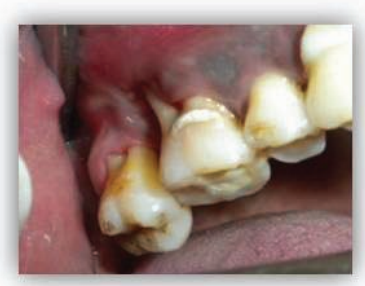

Pre-operative view

Fig -3

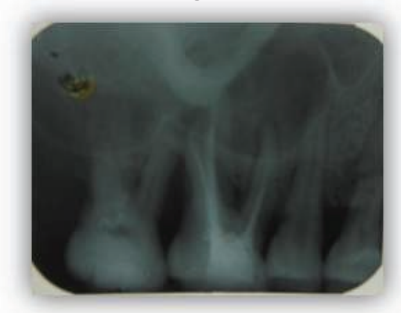

Endodontic treatment done

Fig -5

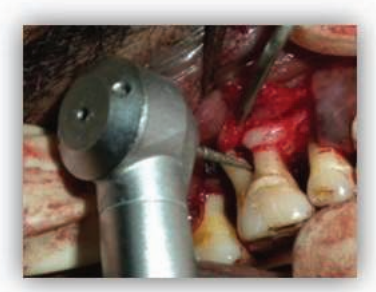

Separation of disto-buccal root by No. 2 carbide bur
Fig -2

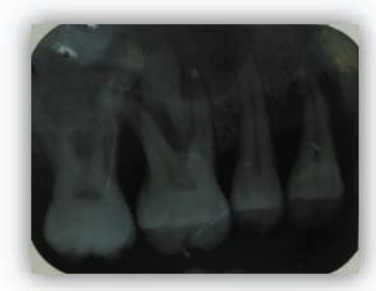

Pre-operative IOPA

Fig -4

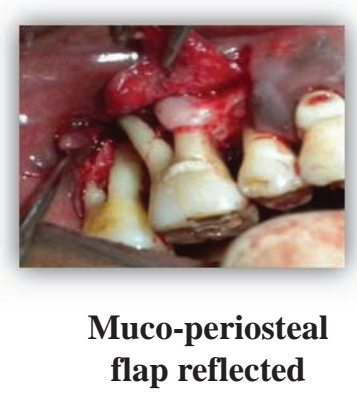

Fig -6

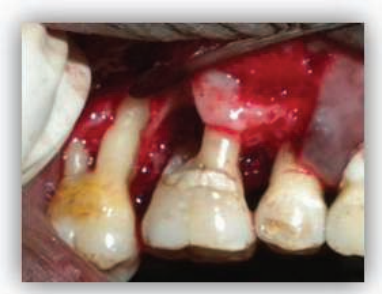

Debridement \& odontoplasty done
Fig -7

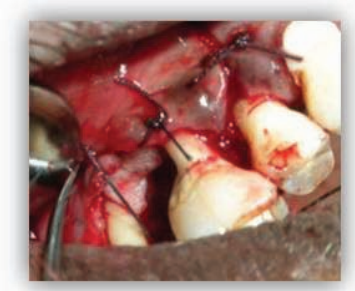

Bone graft and PRF membrane placed

Fig -9

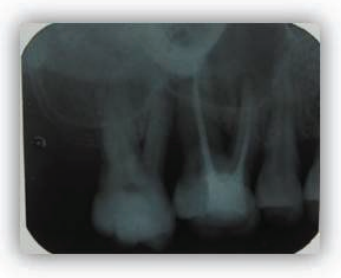

Post operative IOPA

Fig -11

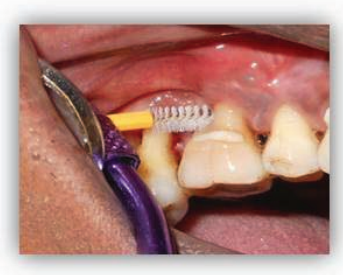

Maintenance by interproximal brush

\section{Discussion}

The empty socket was thoroughly curetted and syringeable bone graft material (Nova bone putty) was used to fill the defect and platelet rich fibrin membrane placed over the grafted site (Fig-7) and flap was sutured back with resorbable 4-0 Vicryl suture and periodontal dressing was placed (Fig-8).

Patient was prescribed Cap Amoxicillin 250mg BID, Tab Metronidazole 400mg TID and Tab Aceclofenac-100mg and Paracetamol-500mg with Serratiopeptidase $15 \mathrm{mg}$ BID for 5 days and post operative instructions were reinforced (Fig-11). Post operative radiograph was taken (Fig-9). Sequential follow up visits was done at 1 week, 4 weeks, 4 months and 6 months.The full metal crown restoration in relation to 16 (Fig-12) was cemented using resin cement. Follow up visits showed no abnormal soft tissue and radiological hard tissue changes (Fig-10). Sequential radiographs revealed radioopacity suggestive of bonefill.

When a clinician cannot make a definitive diagnosis in the case of an endo-perio lesions, it may be prudent for him or her to initiate either of the management modalities and hope for repair.However, this could be overcomeby proper history taking and sequential treatment planning. ${ }^{2}$ Successful management to retain furcation involved teeth remains one of the in most difficult treatments and thought to have a strong negative effect on prognosis in overall periodontal therapy.Treatment of Endoperio lesions have always been challenging for the dentists; especially when complicated by furcation involvement. ${ }^{7}$ Furcation treatment and outcomes with open flap debridement and bone grafting depends majorly on the vertical and horizontal component of bone loss and intactness of buccal and lingual cortical bone plates. ${ }^{7}$

Farrar in 1884 introduced Root resective procedures which has been used to treat class II and III furcation involved molars. ${ }^{8}$ 
Root resection is the process by which one or more of the roots of a tooth are removed at the level of the furcation while leaving the crown and remaining roots in function. ${ }^{9}$ Root resection was done for molars especially maxillary molars with periodontal, endodontic,restorative or prosthetic problems.It is very technique sensitive and complex procedure,thus proper case selection is essential. ${ }^{10}$ The purpose of root resective therapy is to convert furcation involved molars to nonfurcation-involved teeth and providing a favourable environment for oral hygiene to the patient. ${ }^{11}$ In the reportedcase root resection of distobuccal root of 16 was planned mainly due to furcation involvement and bone loss.

The reason why resection of disto-buccal root of maxillary first molar was done because ${ }^{5}$ :

- Severe distal curvature of disto-buccal root

- Maximum concavity on the distal aspect of the distobuccal root.

- The minimum mesio-distal dimension of distobuccal root

- Width of the residual interradicular septum -Thin.

- Distance from the pulp chamber floor to the root separation on the distal aspect of root is less.
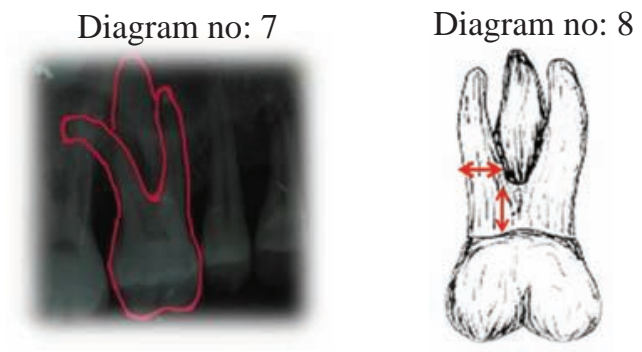

Root-resection therapy is still a valid treatment option for molars with furcation involvement and severe bone loss in cases of combined perio-endo lesions. Root resection as been considered in this case to retain the tooth and thus avoiding extraction of natural tooth. Studies have shown better prognosis of teeth with root resection performed for periodontal problem when compared to root resection performed for non periodontal purposes. However periodontal problem around resected molar have a tendency to recur and should be maintained through meticulous supportive periodontal therapy.

Survival and failure rate following root resection ${ }^{12}$ : Several studies have shown that molars that underwent root resection because of periodontal problems had a higher survival rate than those resected because of non-periodontal problems.

- Buhler$^{7}$ (1994)- reported that 89\% of root resected teeth survived over a 7-year period.

- Carnevale et $\mathrm{al}^{13}(1998)$ - reported a $6.9 \%$ failure rate over a 10-year period.

- Hamp et $\mathrm{al}^{14}(1975)$ - reported difficulties with maxillary molar root resection because of unfavourable access and the relationship with the neighbouring teeth.

The survival rate of resected molars might be influenced by a variety of factors. Lang and Tonetti ${ }^{12}$ (1996) suggested that an evaluation of the risk factors for periodontal disease progression was required at the patient, tooth, and site level.

\section{Conclusion}

The prognosis of the combined lesion depends on the treatment plan. The healing of an endodontic lesion is highly predictable. The periodontal component of a combined lesion is a more difficult problem even with periodontal treatment, the periodontal defect typically does not resolve to the same extent as the endodontic lesion. The ability to eliminate the periodontal component of the defect ultimately dictates treatment of the tooth. Therefore the decision to treat and retain teeth with combined periodontal and endodontic lesions should be carefully considered in regard to the overall dental treatment plan because the time and cost of combined defect treatment may be considerable.

\section{References}

1.Simring M, Goldberg M. The pulpal pocket approach: retrograde periodontitis. J Periodontol 1964; 35: 22-48.

2.Nina S, Arvind S:Endo-perio lesions: Diagnosis and clinical considerations. Indian J Dent Res. 2010;21(4):579-585

3.Simon JH, Glick DH, Frank AL. The relationship of endodontic-periodontic lesions. J Periodontal 1972 ;43: 202-208.

4.DeSanctis M, Murphy KG. The role of resective periodontal surgery in the treatment of furcation defects. Periodontol 2000. 2000;22: 154-168.

5.Shin-Young Park, Seung-Yun Shin. Factors influencing the outcome of root resection therapy in molars; A 10-year retrospective study. J Periodontal 2009: 80:1:32-40.

6.Amarendher RK, Nagalaxmi RS, Prathapkumar M, SambasivaRao P. Treatment of endo-perio lesion with syringeable bio active alloplastic Bone graft material: A case report. Annals and Essences of Dentistry. 2012:4(1):59-62 
7.Buhler H. Evaluation of rootresected teeth. Results after 10 years. J Periodontol. 1988;14:537-543.

8.Farrar JM. Radical and heroic treatment of alveolar abscess by amputation of roots of teeth . Dental Cosmos.1884; 26(2):79-81

9.American Academy of Periodontology. Glossary of Periodontal Terms. Chicago. American Academy of Periodontology. 2001:45.

10.Sunitha R, Munirathnam NE. Platelet rich fibrin: Evolution of a second generation platelet concentrate. Indian J Dent Res. 2008;19:42-46.

11.Nitin H.D, Shahabe A. Saquib. Root Resection: A treatment modality for endoperio lesions. Indian Journal of Dental Sciences;2012:4(3):36-38

12.Lang NP, Tonetti MS. Periodontal diagnosis in treated periodontitis.Why, when and how to use clinical parameters. J Clin Periodontol. 1996;23:240-250.
13.Camevale G, Pontoriero R, di Febo G. Long-term effects of root-resective therapy in furcation-involved molars. A 10-year longitudinal study. J Clin Periodontol. 1998;25:209-214.

14.Hamp SE, Myman S, Lindhe J. Periodontal treatment of multirooted teeth. Results after 5 years. J Clin Periodontol.1975:2:126-135.

15.Glickman I.Clinical Periodontology. 1st Ed. W.B. Saunders Co, Philadelphia; 1953: 545-546.

\section{How to cite this article:}

Pramod VT, Shobhaprakash, Sadiya S. Hopeless to hopeful: Management of an endo-perio lesion with an interdisciplinary approach - A case report: CODS J Dent 2014;6;112-116

Source of support: Nil. Conflict of interest: None Declared. 